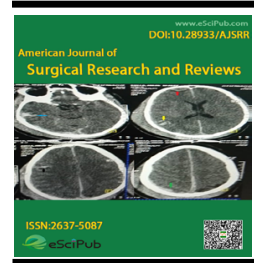
\title{
(ISSN:2637-5087)
}

American Journal of Surgical Research and Reviews

\section{Translational Medicine and Autologous Fat Transfer: From bench to bedside. Regenerative and proliferative potential of adipose tissue}

\author{
Andrea Edoardo Bianchi, MD ${ }^{1,2}$, Antonio Lucchi, MD ${ }^{1}$, Riccardo Luoni Orsi, DMD ${ }^{1}$, Luigi \\ Clauser, MD $^{1}$ \\ ${ }^{1}$ Unit of Maxillo-Facial Surgery, Istituto Stomatologico Italiano, Via Pace, 21, 20122 MILANO, Italy; \\ ${ }^{2}$ University UniCamillus, Via di Sant'Alessandro, 8, 00131 ROME, Italy
}

\section{ABSTRACT}

Aim: Autologous fat transfer (AFT) for the correction of maxillofacial defects was first reported at the end of the 19th century.

*Correspondence to Author:

AFT was introduced as a way of improving facial esthetics and in Prof. Luigi Clauser the last few years has expanded into applications in craniomaxillofacial reconstructive surgery and regenerative therapy. This protocol is part of translational medicine. The aim of translational medicine, or translational science, is to combine disciplines, resources, expertise, and techniques based on three main pillars: bench, bedside, and community. The primary goals to coalesce assets of various natures to significantly improve the global healthcare system. AFT is thus part of translational medicine in tissue healing, regeneration and augmentation.

Methods: Several techniques have been suggested for harvesting and grafting the fat. The Authors follow Coleman's technique with centrifugation and infiltration using different types and sizes of cannulas.

Conclusion: This review provides a fairly comprehensive summary of the many exciting possibilities that exist in the field of facial fat grafting. Five clinical cases are presented and discussed. Translational medicine is the basis of this new reconstructive and regenerative field of science and research.

Unit of Maxillo-Facial Surgery, Istituto Stomatologico Italiano, Via Pace, 2120122 Milano, Italy, Ph +3902541761

How to cite this article:

Andrea Edoardo Bianchi, Antonio Lucchi, Riccardo Luoni Orsi, Luigi Clauser. Translational Medicine and Autologous Fat Transfer: From bench to bedside. Regenerative and proliferative potential of adipose tissue.American Journal of Surgical Research and Reviews, 2021, 4:33.

\section{eScîPub}

eSciPub LLC, Houston, TX USA. Website: https://escipub.com/

Keywords: Regenerative medicine, translational medicine, lipofilling, fat grafting, adipose-derived-stem-cells, fat graft survival, fat graft processing, maxillofacial surgery, soft tissue reconstruction, stem cells, bench to bedside

By using the site/services, you are agreeing to our Policies: https:// escipub.com/terms-privacy-policydisclaimer/ 


\section{INTRODUCTION}

Adipose tissue transfer used for the correction of maxillofacial defects was first reported at the end of the 19th century. Since 1893, some physicians have used fat grafts, the results of which, however, have been unpredictable and extremely technical surgeon-dependant.Several reports in the literature of the early 20th century have described tissue augmentation with different injectable fillers such as gold, rubber latex, guttapercha, paraffin, collagen, Goretex, silicon, and more recently, polylactic acid and Bio-Alcamid. ${ }^{[1,2]}$ Focusing attention on the face, in 1991 the New Yorker Sydney R. Coleman systematized the technique. His philosophy was based on the belief that fat was the ideal filler because it was natural, stable, and without the complications of earlier fillers. AFT is different from other fat grafting techniques, due to its delicate aspiration which protects the fragile adipocytes, favors the purification of the material, and facilitates its reinsertion using microinjections to redefine facial contours and create a more harmonious and esthetically appealing proportion of the face. ${ }^{[3,4]}$ Moreover human adipose tissue is a rich source of mesenchymal stem cells because they exhibit multilineage potential and secrete angiogenic and antiapoptotic factors. [5,7] The main indications for AFT are for: restoration and soft tissue facial reconstruction after trauma, tumour resection, congenital deformities and clefts, Parry-Romberg syndrome and scleroderma, orbital and periorbital surgery, facial palsy, burns, and scars. ${ }^{[8,15]}$ AFT is also used for the rejuvenation of the face in areas such as the forehead, zygomas, lips, nose, chin, mandible and jawline. [16,17,18,19,20]

\section{MATERIALS AND METHODS}

Indications for fat grafting are increasing. There are three types of fat dimensions and thus different indications, depending on the type of laboratory preparation. The first sample is the classic lipoaspirate macrofat, the second is the microfat harvested with a small-hole cannula, and the third is the microfat processed into nanofat. Nanofat seems to be suitable for skin rejuvenation purposes. ${ }^{[21,22]}$ Given the type of pathology and fat transfer, this article describes only cases that were treated following Coleman's technique. Five patients scheduled to undergo AFT in the maxillofacial area are presented. All received general or local anesthesia with sedation. As a document and for comparison, frontal, three-fourths view, lateral, sub-cranial, and close-up photos were taken preoperatively and during the follow-up.

\section{Analysis of the Patient. Fat Harvesting Technique}

The preoperative plan included a full patient's photographic study in different facial projections and views with creation of blueprints, according to Coleman's guidelines .Different colored pencils were used on the blueprints to mark the areas that were to be injected, those not injected, and, if necessary, areas where excessive fat tissue needed to be removed. These markings were also duplicated on the patient's face preoperatively. Patients must be fully informed, with an informed consent, on the procedure before surgery regarding what they can expect on the day of surgery, and on the expected postoperative course.On the day of surgery,the blueprints are reviewed and the plan discuss again with the patient.The operation starts with fat aspiration from the donor sites using a very thin liposuction cannula attached to a $10-\mathrm{mL}$ Luer-Lock syringe for suction. During the fat removal, care was taken to reduce mechanical trauma to the adipocytes. There are two types of fat grafting: non-enriched fat grafting and cell enriched fat grafting (stromal, vascular fraction isolation or culture expanded stem cells), which is promising but an undertested therapeutic option for improving graft retention. We are still in the phase of technical evolution and research to achieve the best clinical application and results.

\section{Fat Processing. Centrifugation, Refinement, Purification}

According to Coleman's technique, once the fat has been removed, each $10 \mathrm{~mL}$ syringe is 
carefully placed into a sterilized sleeve in a sterilized central rotor of a centrifuge and spun at approximately $1,300 \mathrm{rpm}$ for 3 minutes. The fat separates into three layers, the top being composed primarily of oil from ruptured fat parcels, the bottom layer of blood, and the middle layer of usable adipose tissue. The top oil is decanted and the dense lowest layer is drained. The refined parcels of fat in the middle are then transferred to a $1-\mathrm{mL}$ syringe and layered into the areas requiring enhancement, working from the underlying bone up to the skin surface (FIGURES $1 \mathrm{~A}, \mathrm{~B}, \mathrm{C}, \mathrm{D}, \mathrm{E}, \mathrm{F}$ )
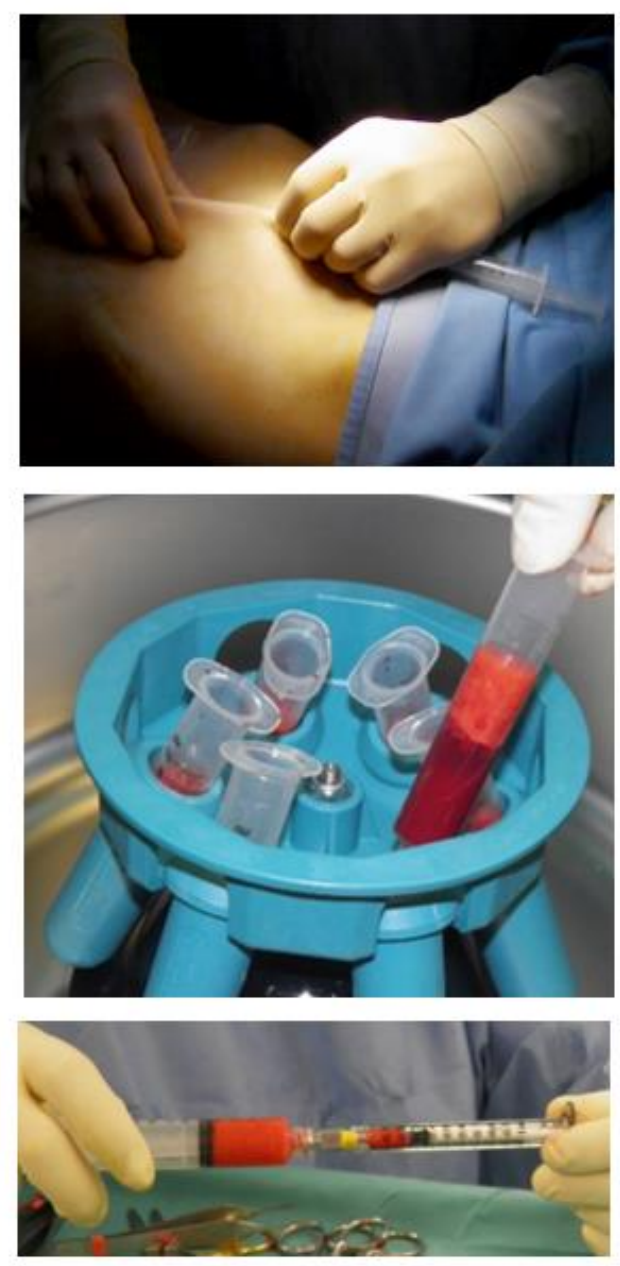
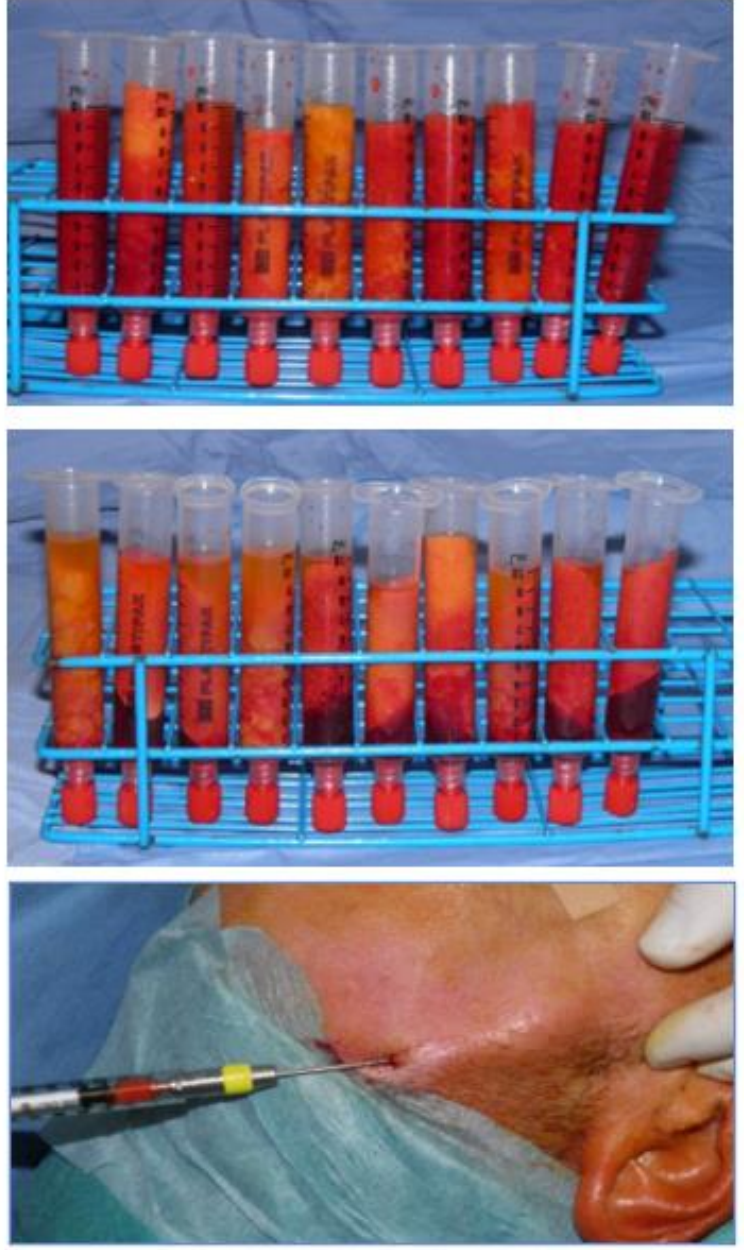

Figure $1 \mathrm{~A}, \mathrm{~B}, \mathrm{C}, \mathrm{D}, \mathrm{E}, \mathrm{F}$ : Fat harvesting, processing, placement procedure. Fat harvesting from the donor area, abdomen in this case (A).The fat is aspirated in a $10 \mathrm{cc}$ syringes (B), positioned in a centrifuge and centrifugated, $1.300 \mathrm{rpm}$ for 3 minutes(C). Syringes after centrifugation show three distinct layers: oil on the top, fat in the middle, blood in the lowest part(D).Oil and blood are discharged and pure middle layer of fat transferred into a $1 \mathrm{cc}$ syringe $(E)$ and then injected and placed in the facial planned area. $(F)$.

\section{Fat Transfer and Placement Technique}

Cannulas with different tips, shapes, diameters, lengths, and curves can be used.The use of blunt cannulas allows placement of the fat parcels in a more stable and less traumatic manner. However, less blunt cannulas may give the surgeon more control for placement in the immediate subdermal plane, in fibrous tissue, and in scars. A cannula with pointed or sharp elements is used to free up adhesions and scars. Fatty tissue should be injected only as the cannula is withdrawn. With linear deposition, the fat is layered into the area needing enhancement, working from the underlying bone 
up to the skin surface to produce a threedimensional grill in a fan-like pattern. The largest amount of tissue that should be placed with each withdrawal of a cannula is $1 / 10 \mathrm{~mL}$, but in some areas, such as the eyelid, the maximum placed should be from $1 / 30$ to $1 / 50 \mathrm{~mL}$ per withdrawal. A substantial one-step correction, using more fat tissue must be avoided because it can cause poor vascularization and more reabsorption, particularly in areas covered by a thin layer of tissue.The technique allows the fat to be carefully layered into minuscule strands creating a large contact surface area-with the augmented site, thus ensuring that nutrition can be exchanged through capillaries in the enveloping tissue. ${ }^{[23]}$ This is essential for the fat to survive. By using the patient's own fat, there is no risk of allergic reactions or rejections by the body. The deeply embedded fat does not shift or migrate.New disposable equipments, in different sizes and shapes, are today available.
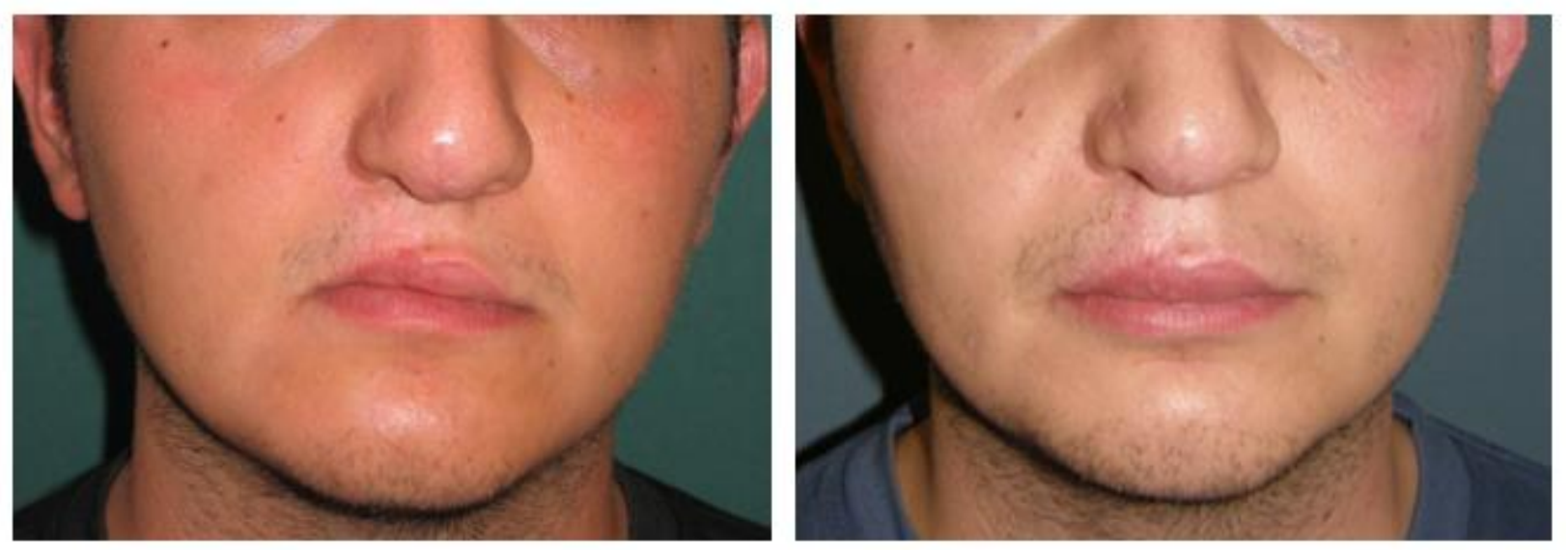

Figure 2 Before $(A)$ and after $(B)$ the correction of cleft lip and palate,deformity. Fat grafting and volume augmentation was the last procedure, after nose and lip reconstruction.

\section{Postoperative Period and Stability of Transplanted Fat}

After surgery, compression dressings are applied around the infiltrated areas. The patient wears an abdominal binder if the fat is harvested from the abdomen. For 24 to 36 hours postoperatively, ice packs are applied continuously on all infiltrated sites. Postoperative care involves use of antibiotics for several days and anti-inflammatory therapy and massage of donor area to relieve swelling and bruising. Patients must be instructed that postoperative swelling can last for 2-3 weeks. Recovery time and downtime will vary, depending on the extent of the procedure and on the type of patient and pathology. The fat can be slowly absorbed by the body, although the amount of absorption is variable and frequently unpredictable. [24] The percentage of reabsorption depends on the patient, pathology and surgeon's technique. When a significant amount of fat is absorbed, a second or third procedure may be necessary to achieve the best final and stable result. After each procedure the lapse of time usually varies from 5 to 8 months. In recent years several attempts have been made to identify agents that increase fat graft viability and survival rate. One of these agents is growth factor. Growth factors may increase graft survival rate and maintain fat graft volume: In addition to fat grafts, several different types of growth factors have been proposed. Several studies found that the addition of growth factors improves the overall graft survival rate in vitro and in vivo. However the exact molecular mechanism has yet to be established. ${ }^{\text {[25] When }}$ dealing with craniofacial deformities, one should bear in mind that patients have altered growth potential. Fat reabsorption is higher in these patients compared with others, and AFT should 
be done as many as 4 to 5 times to improve, fix and stabilize the final result, with a lapse of 8-12 months.

\section{Clinical cases}

\section{Patient 1 - FIGURE 2 A, B}

Sequelae of cleft lip, nose and palate. After the standard sequential protocol for cleft lip palate and nose repair, a total of $30 \mathrm{cc}$ of fat was injected in the perioral area of the lip, bilaterally in 2 stages ( $14 \mathrm{cc}$ the first and $16 \mathrm{cc} 8$ months later). Two-year follow up after the last fat injection with good reshaping of the oral-perioral area and nose.
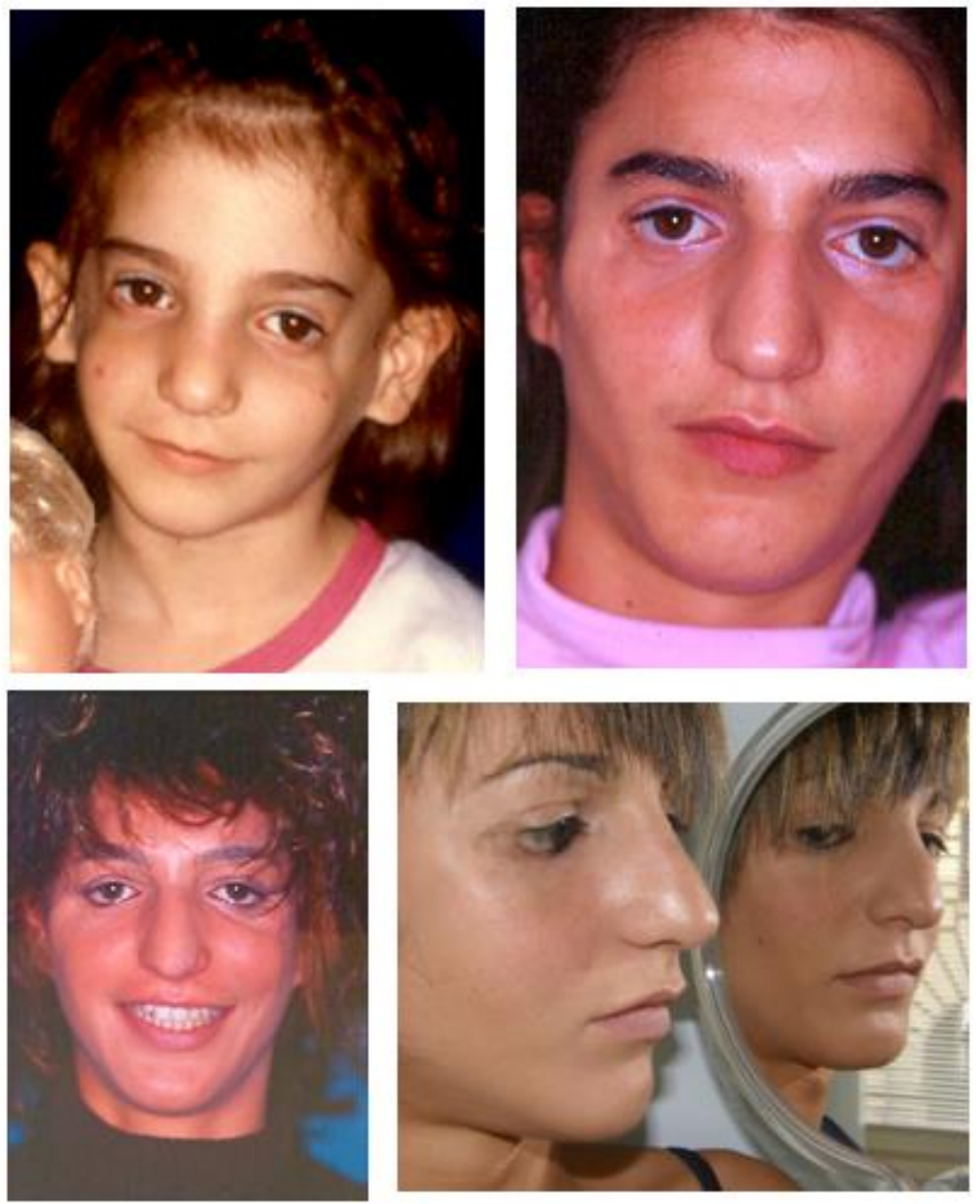

Figure 3 Treacher Collins Syndrome (A). First stage was orbito-zygomatic reconstruction with cranial bone at age $6(\mathrm{~B})$. Other surgeries followed $(\mathrm{C})$. At the end of the skeletal reconstruction, fat transfer, in 3 stages, improved volumes, regeneration and the overall aspect of the patient, now age 21 (D).

\section{Patient 2 - FIGURE 3 A, B, C, D}

Treacher Collins syndrome. The protocol of treatment started at age 6 . The main reconstructive step was bilateral orbitozygomatic reconstruction using cranial bone grafts. Then, rotation of skin muscle flap from the upper eyelids to the lower eyelids to increase lower eyelid soft tissue deficiency. Advanced jumping genioplasty followed. To augment the soft tissue volumes, at the age of 19 , three stages of AFT were planned with a total amount of $180 \mathrm{cc}$ of fat within a lapse of time of about 67 months.

AJSRR: https://escipub.com/american-journal-of-surgical-research-and-reviews/ 

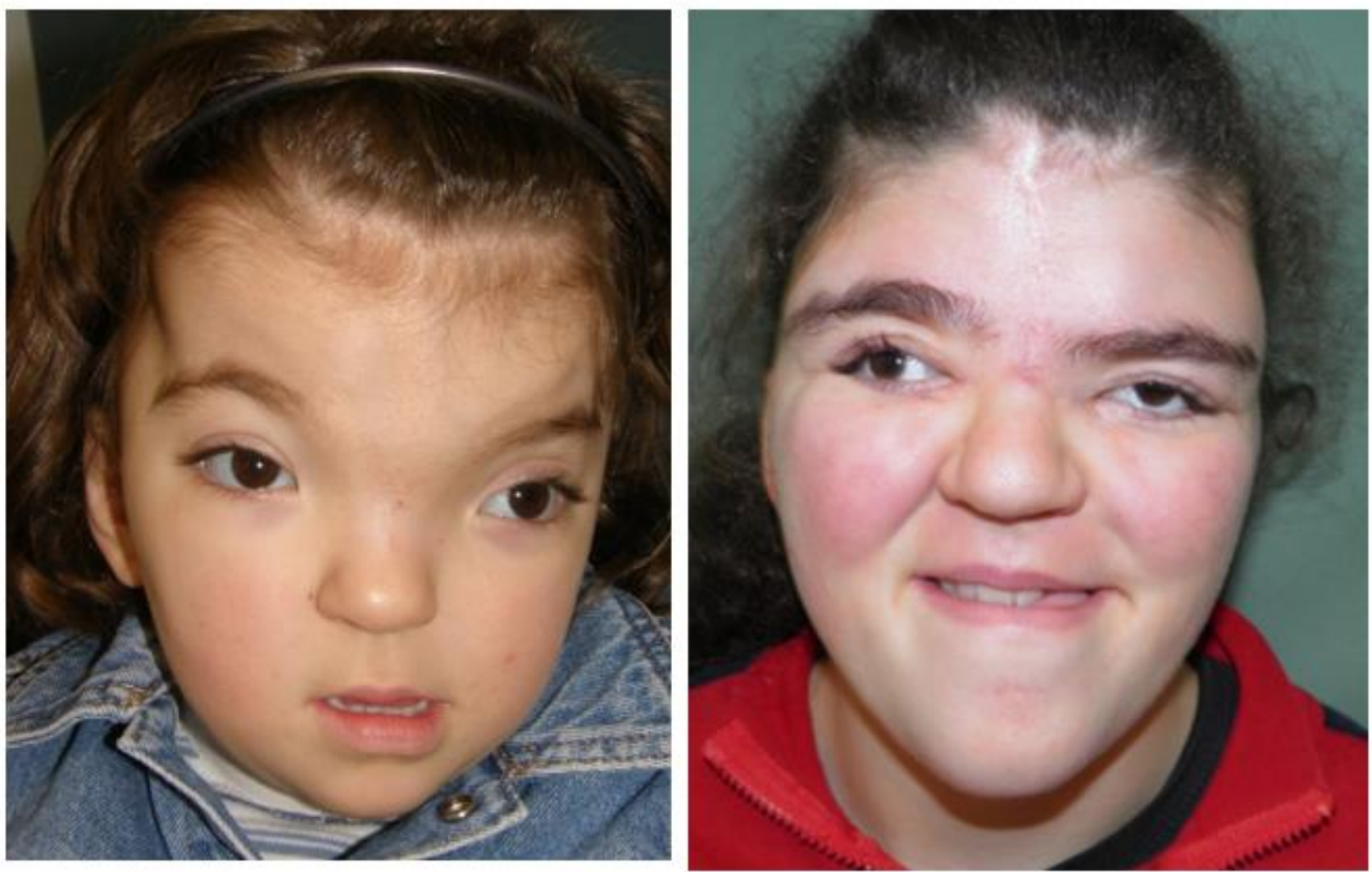

Figure 4 Severe syndromic craniofacial deformity with hypertelorbitism( Tessier Cleft 0-14 type), after many surgical facial and craniofacial procedures: facial bipartition, orbital boxes repositioning, nasal reconstruction,orbital surgery (A). At the end of the first bony reconstruction stage,Fat transfer improved the paucity of soft tissue with facial augmentation reducing the facial skeletonizd aspect (B). More bony and soft tissue surgeries are planned in the near future and during the adulthood.
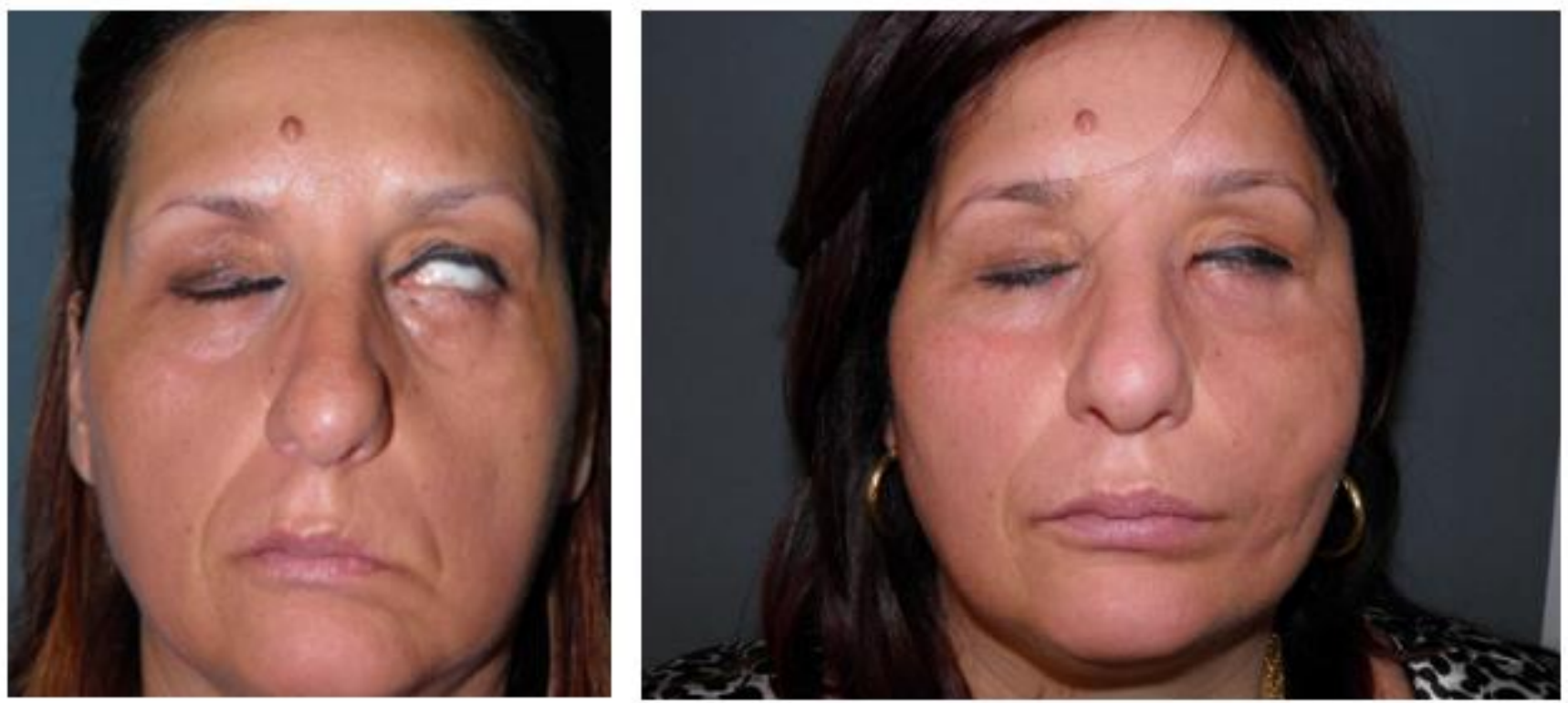

Figure 5 Left VII nerve palsy before (A) and after (B) temporalis muscle flap transposition, eyelids reahanimation with blink restoration. Static procedure with fascia lata for suspension of the oral commissure was performed in another stage. At the end, total facial fat grafting with facial augmentation improved and reduced the facial paralysis stigmata. 

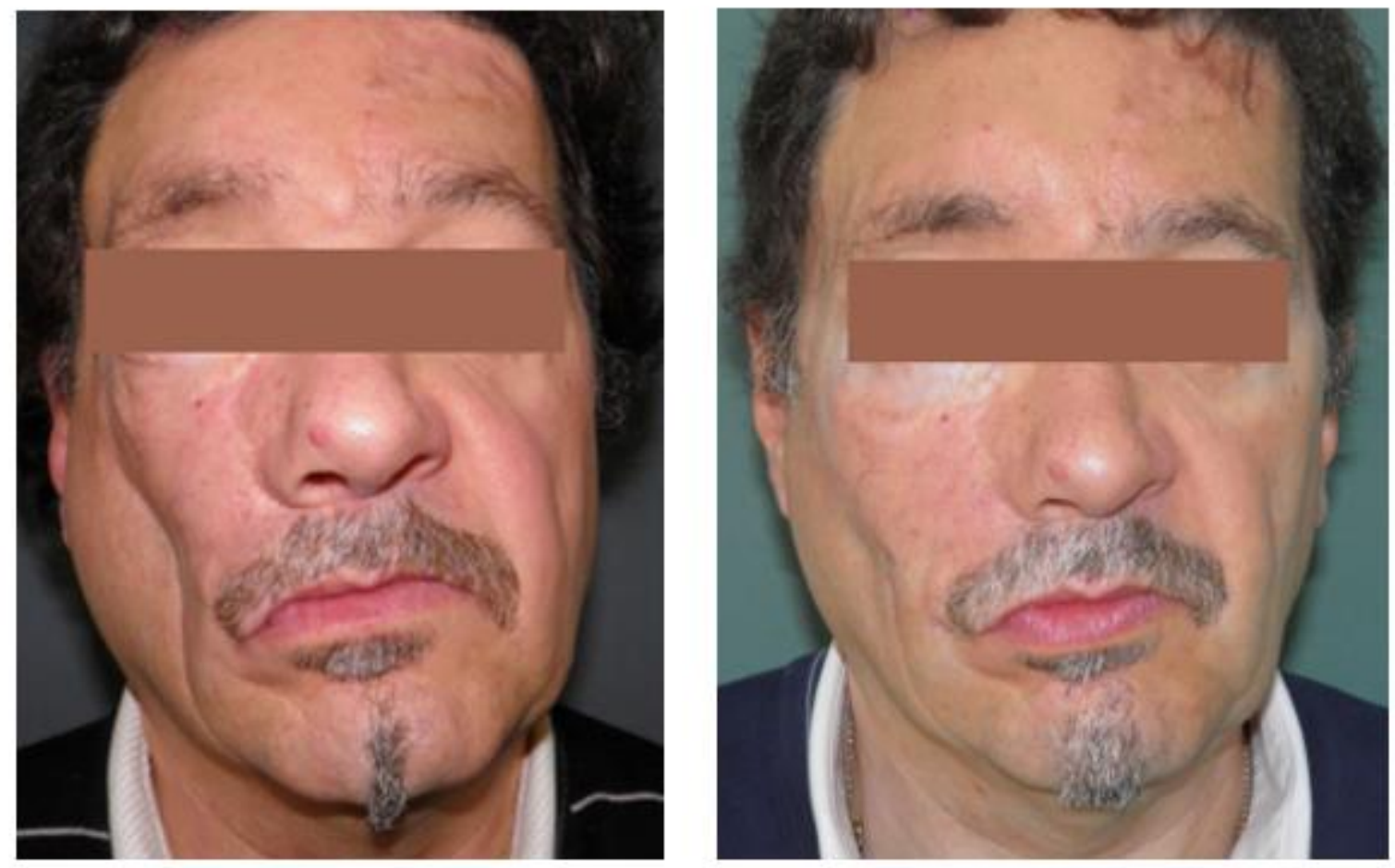

Figure 6 Gunshot wound is another indication for AFT. The patient before (A) and after (B) many soft tissue reconstructive surgeries and bilateral facial fat transfer to the entire midface, jawline, perioral, lips,chin area.

\section{Patient 3 - FIGURE 4 A, B}

Severe form of syndromic craniofaciostenosis with bifid nose, hypertelorbitism, orbital dystopia, strabismus (Tessier cleft type 0-14).

At age 6 hypertelorbitism correction with nasal reconstruction was performed, followed by different surgeries in various steps (nose, orbits, eyelids). The deficit of facial volume was corrected by serial AFT (total $125 \mathrm{cc}$ of fat) in a time lapse of about 7 months from each other. The result at age13. More surgeries are planned in the near future and after adulthood.

\section{Patient 4 - FIGURE 5 A, B}

Sequelae of VII left cranial nerve palsy. Left eye blink restoration was obtained by temporalis muscle fascial flap transposition. The left oral asymmetry was corrected with static suspension, fascia lata sutured at the temporalis arch and commissura.AFT improved the hemifacial atrophy due to the long-standing facial palsy. A total amount of $100 \mathrm{cc}$ of fat in two procedures was injected bilaterally to augment the overall ptotic facial soft tissue volumes.

\section{Patient 5 - FIGURE 6 A, B}

Right gunshot wound sequelae. Before and after injection of a total of $115 \mathrm{cc}$ in two lipofilling stages, improved the periorbital and right cheek deformity. Fat acted as genuine natural permanent filler with tissue-regenerative qualities to the recipient site.

\section{Discussion}

AFT introduced as a way to improve facial esthetics and recently has evolved into applications in more complex reconstructive procedures. Fat grafting provides a technique whose biocompatibility easily adapts to the growth of the face over time. It has lower morbidity compared with many other alloplastic materials, which often lead to the reactions caused by foreign bodies, making it the ideal tool for the correction of localized tissue atrophy: loss of substance due to trauma, posttumour and congenital complex craniofacial anomalies; burns, as well as hemifacial atrophy, that is, Parry-Romberg syndrome and scleroderma. Results are natural and long-lasting.AFT is 
different from other fat grafting techniques because of the harvesting, purification, and placement. Different kinds of needles have been used for harvesting because minimum trauma to the adipocytes is of paramount importance. ${ }^{[25]}$ There are four principal ways to purify adipose tissue: centrifugation, filtration, decantation, and washing. Although AFT it is a safe procedure, complications may occur. The most frequent problems and complications are: overundercorrection, lumps and bumps, oil cysts, reabsorption, fat migration, infection, damage to underlying structures and ischemic necrosis. Fat embolism have been reported in a few cases. [26${ }^{28]}$ Particular applications of AFT are recalcitrant ectropion, anophthalmic socket, orthognathic surgery and scars or burn wounds. Ectropion (post-trauma, congenital, different postreconstructions) is a challenging situation. Many techniques have been described and reported, some as successful and others as not. The basic problem of the ectropion is the shortage of skin, muscles, and internal lamellae. A palatal mucosal graft to rebuild the internal lamella is very useful but it does not restore the skin and orbicularis muscle. Lengthening of the internal lamella can be combined (in a second stage) with small drops of fat. The result is an extension of the lower eyelid with improvement in volume and texture. ${ }^{[29]} \mathrm{AFT}$ in orthognathic surgery is another application for soft tissue augmentation. It is well known that orthognathic surgery moves only the skeletal bases:maxilla, mandible, and chin. Soft tissue deficiency can be augmented and improved with AFT.

\section{Adipose-derived stem cells: potential for clinical applications}

Results of different studies have proven that human adipose tissue is a rich source of mesenchymal stem cells (ADSCs), exhibiting multilineage potential and featuring secretion of angiogenic and antiapoptotic factors. ADSCs are isolated from the vascular stromal component of lipoaspirate. A standard raw lipoaspirate is composed of mature adipocytes, extracellular matrix, ADSCs, endothelial cells, and mural cells (pericytes and vascular smooth muscle cells). When enzymatically digested, the nonbuoyant cellular fraction forms the stromal vascular fraction and contains ADSCs, vascular progenitor cells, pericytes, and endothelial cells. Although ADSCs are of mesodermal origin, they have the potential, under the appropriate conditions, to differentiate into multiple lineages of adipogenic, osteogenic, chondrogenic, myogenic, cardiomyogenic, and neurogenic cells. Recent studies also show that ADSCs are able to differentiate into tissues of ecto-and endodermal lineages such as neural cells, hepatocytes, pancreatic islet cells, endothelial cells, and epithelial cells. Evidence exists that stem cells contribute to the restoration of tissue vascularization and organ function. Consequently adipose tissue has a potential clinical use for cellular therapy, tissue engineering, and gene transfer applications in regenerative medicine. ${ }^{[30]}$ The study by Rigotti et al. shows the therapeutic efficacy of ADSCs for the treatment of radiation-induced damage through a process of replacement of damaged tissue with reconstructed normal tissue. [31] ADSCs could be considered in the treatment of neurologic or different types of disorders, including maxillofacial problems, acquired and congenital deformities and diseases. ${ }^{[32]}$

\section{Conclusion}

Autologous fat transfer, introduced as a way of enhancing facial esthetics, has developed in the last two decades into more complex reconstructive and regenerative procedures. The technique should be part of the armamentarium of modern reconstructive surgeons not only as an ancillary treatment, but also as a basic surgical technique. AFT is an excellent tool for cranio-maxillofacial surgery as it accomplishes natural results that stand the test of time. Today, tissue engineering and regenerative medicine are part of a multidisciplinary science that is expanding along with biotechnological advances. The proposed uses for ADSCs in tissue repair/regeneration are quite impressive. Recent works on ADSCs 
would suggest that this adult stem cell might prove to be an equally powerful tool in treating congenital and acquired disorders. [33] Nonetheless, the availability and the processes for obtaining stem cells remain a challenge for both surgeon and scientist pursuing regenerative medicine. Today, fat grafting has achieved the status of a widely recognized and worldwide performed procedure among laboratory research and evolution. Translational medicine could be very helpful in providing alternatives, new concepts, indications with improvements in the clinical practice.

\section{DECLARATIONS}

Authors' Contributions: Andrea Edoardo Bianchi and Luigi Clauser designed the clinical data and research; Luigi Clauser,Antonio Lucchi and Riccardo Luoni Orsi performed surgical treatments and samples collection;Andrea Edoardo Bianchi and Luigi Clauser prepared the article.

\section{Availability of data and materials}

Not applicable

\section{Financial support and sponsorship}

None

\section{Conflicts of interest}

All Authors declared that there are no conflicts of interest

\section{Ethical approval and consent to participate}

Not applicable

\section{Consent for publication}

Written informed consent was obtained for all patient images.

\section{Copyright}

CThe Authors (2021)

\section{References}

[1]. Coleman SR. Facial recontouring with lipostructure. Clin Plast Surg 1997;24(2):347367

[2]. Coleman SR. Structural fat grafts: the ideal filler? Clin Plast Surg 2001;28(1):111-119

[3]. Coleman SR, ed. Structural Fat Grafting. Saint Louis, MO: Quality Medical Publishing Inc; 2004

[4]. Rigotti G, Marchi A, Sbarbati A. Adipose-derived mesenchymal stem cells: past, present, and future. Aesthetic Plast Surg 2009; 33(3):271273

[5]. Strem BM, Hicok KC, Zhu M, et al. Multipotential differentiation of adipose tissue-derived stem cells. Keio J Med 2005;54(3):132-141

[6]. Fraser JK, Wulur I, Alfonso Z, Hedrick MH. Fat tissue: an underap- preciated source of stem cells for biotechnology. Trends Biotechnol 2006;24(4):150-154

[7]. Moseley TA, Zhu M, Hedrick MH. Adiposederived stem and progenitor cells as fillers in plastic and reconstructive surgery. Plast Reconstr Surg 2006;118(3, Suppl):121S-128S

[8]. Clauser L.et al.Structural fat grafting: facial volumetric restoration in complex reconstructive surgery. J Craniofac Surg 2011;22(5):16951701

[9]. Clauser L.et al. Integrated reconstructive strategies for treating the anophthalmic orbit. J Craniomaxillofac Surg 2004;32(5):279-290

[10]. Clauser $L$ et al. Optimizing maxillofacial and craniofacial results. Presented at: American Society of Plastic Surgeons Annual Meeting; October 2009; Seattle, WA

[11]. Clauser L. Optimizing maxillofacial and craniofacial results. In: Coleman SR, Mazzola $\mathrm{RF}$, eds. Fat Injection From Filling to Regeneration. Saint Louis, MO: Quality Medical Publishing Inc; 2009: 475-500

[12]. Clauser L. et al Autologous fat transfer for facial augmentation and regeneration: Role of Mesenchymal stem cells-. Atlas of the Oral and Maxillofacial Surgery Clinics, Editors: Bagheri,H.Khan, B.Bohuli - Elsevier 2018

[13]. Clauser L. Facial Lipostructure: an overview I. American Journal of Surgical Research and Reviews, 2021, 4:20 doi.org/10.28933/ajsrr2021-05-1206

[14]. Clauser L. Autologous Facial Fat Transfer: Soft Tissue Augmentation and Regenerative Therapy. J of Craniofacial Surgery, 31, 7 October 2020, 1879 - 1882.

[15]. Giugliano C, Benitez S, Wisnia P, Sorolla JP, Acosta S, Andrades P. Liposuction and lipoinjection treatment for congenital and acquired lipodystrophies in children. Plast Reconstr Surg 2009; 124(1):134-143

[16]. Coleman SR, Saboeiro A, Sengelmann R. A comparison of lipoa- trophy and aging: volume deficits in the face. Aesthetic Plast Surg 2009;33(1):14-21

[17]. Foyatier JL, Mojallal A, Voulliaume D, Comparin J-P. [Clinical evaluation of structural fat tissue graft (Lipostructure) in volumetric facial restoration with face-lift. About 100 cases]. Ann Chir Plast Esthet 2004;49(5):437-455 
[18]. Bucky LP, Kanchwala SK. The role of autologous fat and alternative fillers in the aging face. Plast Reconstr Surg 2007;120(6, Suppl):89S-97S

[19]. Mojallal A, Foyatier JL. [The effect of different factors on the survival of transplanted adipocytes]. Ann Chir Plast Esthet 2004; 49(5):426-436

[20]. Tonnard P,Verpaele A, et al. Nanofat Grating: Basic research and Clinical applications.Plast Reconstr. Surg. 2013;132(4):1017-1026

[21]. Tonnard P,Verpaele A,Carvas M, Fat Grating for facial rejuvenation with nanofat grafts

[22]. Clin Plast Surg 2020 Jan:47(1) 53-62 doi: 10.1016/j.cps.2019.08.006

[23]. Kawamoto HK. Fat injection and craniofacial surgery. In: Coleman SR, Mazzola RF, eds. Fat Injection From Filling to Regeneration. Saint Louis, MO: Quality Medical Publishing Inc; 2009:447-474

[24]. Coleman SR. Long-term survival of fat transplants: controlled demonstrations. Aesthetic Plast Surg 1995;19(5):421-425

[25]. Sarkarat F.,Roozbbeh K. Fat grat with growth factors.Atlas oral and Maxillofacial Surgery Clin.N Am 26(2018) 33-39 doi.org/10.1016/j.cxom.2017.10.003

[26]. Gutowski KA; ASPS Fat Graft Task Force. Current applications and safety of autologous fat grafts: a report of the ASPS fat graft task force. Plast Reconstr Surg 2009;124(1):272-280

[27]. Glasgold RA, Glasgold MJ, Lam SM. Complications following fat transfer. Oral Maxillofac Surg Clin North Am 2009;21(1):5358, vi

[28]. Lee DH, Yang HN, Kim JC, Shyn KH. Sudden unilateral visual loss and brain infarction after autologous fat injection into nasolabial groove. Br J Ophthalmol 1996;80(11):1026-1027

[29]. Caviggioli F, Klinger F, Villani F, Fossati C, Vinci $\mathrm{V}$, Klinger M. Correction of cicatricial ectropion by autologous fat graft. Aesthet- ic Plast Surg 2008;32(3):555-557

[30]. Zuk PA. The adipose-derived stem cell: looking back and looking ahead. Mol Biol Cell 2010;21(11):1783-1787

[31]. Rigotti G, Marchi A, Galiè M, et al. Clinical treatment of radiother- apy tissue damage by lipoaspirate transplant: a healing process mediated by adipose-derived adult stem cells. Plast Reconstr Surg 2007;119(5):1409-1422, discussion 1423-1424

[32]. Kokai LE, Rubin JP, Marra KG. The potential of adipose-derived adult stem cells as a source of neuronal progenitor cells. Plast Reconstr Surg 2005;116(5):1453-1460
[33]. Shih L, et al. Semin Plast Surg. 2020. PMID: 3207157

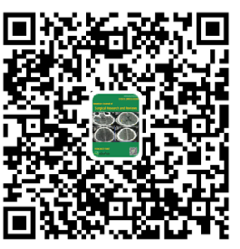

